\title{
Multi-center transferability of a breath-hold T2 technique for myocardial iron assessment
}

\author{
Taigang $\mathrm{He}^{* 1,2}$, Paul Kirk ${ }^{1,2}$, David N Firmin 1,2, Wynnie M Lam³, \\ Winnie CW Chu ${ }^{3}$, Wing-Yan $\mathrm{Au}^{4}$, Godfrey CF Chan ${ }^{5}$, Ru San Tan ${ }^{6}$, Ivy Ng7, \\ Selen Biceroglu ${ }^{8}$, Yesim Aydinok ${ }^{8}$, Mark A Fogel ${ }^{9}$, Alan R Cohen ${ }^{9}$ and \\ Dudley J Pennell1,2
}

\author{
Address: ${ }^{1}$ National Heart and Lung Institute, Imperial College London, UK, ${ }^{2}$ Cardiovascular Magnetic Resonance Unit, Royal Brompton Hospital, \\ London, UK, ${ }^{3}$ Department of Diagnostic Radiology \& Organ Imaging, Prince of Wales Hospital, the Chinese University of Hong Kong, China, \\ ${ }^{4}$ Department of Medicine, Queen Mary Hospital, University of Hong Kong, China, ${ }^{5}$ Department of Pediatrics and Adolescent Medicine, Queen \\ Mary Hospital, University of Hong Kong, China, ${ }^{6}$ National Heart Center, Singapore, ${ }^{7} \mathrm{KK}$ Women's and Children's Hospital, Singapore, \\ ${ }^{8}$ Department of Pediatric Hematology \& Radiology, Ege University Hospital, Izmir, Turkey and ${ }^{9}$ Children's Hospital of Philadelphia, USA \\ Email: Taigang He* - h.taigang@rbht.nhs.uk; Paul Kirk - p.kirk@imperial.ac.uk; David N Firmin - d.firmin@imperial.ac.uk; \\ Wynnie M Lam - wynnie@cuhk.edu.hk; Winnie CW Chu - winnie@med.cuhk.edu.hk; Wing-Yan Au - auwing@hotmail.com; \\ Godfrey CF Chan - gcfchan@hkucc.hku.hk; Ru San Tan - tan.ru.san@nhc.com.sg; Ivy Ng - Ivy.Ng@kkh.com.sg; \\ Selen Biceroglu - selenbicer@gmail.com; Yesim Aydinok - yesim.aydinok@ege.edu.tr; Mark A Fogel - fogel@email.chop.edu; \\ Alan R Cohen - cohen@email.chop.edu; Dudley J Pennell - d.pennell@imperial.ac.uk \\ * Corresponding author
}

Published: 2I February 2008

Journal of Cardiovascular Magnetic Resonance 2008, 10:II doi:I0.1 I86/1532-429X-10-I I
Received: 7 February 2008

Accepted: 2I February 2008

This article is available from: http://www.jcmr-online.com/content/I0/I/II

(c) 2008 He et al; licensee BioMed Central Ltd.

This is an Open Access article distributed under the terms of the Creative Commons Attribution License (http://creativecommons.org/licenses/by/2.0), which permits unrestricted use, distribution, and reproduction in any medium, provided the original work is properly cited.

\begin{abstract}
Background: Cardiac iron overload is the leading cause of death in thalassemia major and is usually assessed using myocardial $\mathrm{T}^{*}$ measurements. Recently a cardiovascular magnetic resonance (CMR) breath-hold T2 sequence has been developed as a possible alternative. This cardiac T2 technique has good interstudy reproducibility, but its transferability to different centres has not yet been investigated.
\end{abstract}

Methods and Results: The breath-hold black blood spin echo T2 sequence was installed and validated on I.5T Siemens MR scanners at 4 different centres across the world. Using this sequence, 5-10 thalassemia patients from each centre were scanned twice locally within a week for local interstudy reproducibility $(n=34)$ and all were rescanned within one month at the standardization centre in London (intersite reproducibility). The local interstudy reproducibility (coefficient of variance) and mean difference were $4.4 \%$ and $-0.06 \mathrm{~ms}$. The intersite reproducibility and mean difference between scanners were $5.2 \%$ and $-0.07 \mathrm{~ms}$.

Conclusion: The breath-hold myocardial T2 technique is transferable between Siemens scanners with good intersite and local interstudy reproducibility. This technique may have value in the diagnosis and management of patients with iron overload conditions such as thalassemia.

\section{Introduction}

The development of transfusion related iron overload in the tissue of myocardium can result in cardiomyopathy $[1,2]$, and heart failure remains the leading cause of death 
in beta-thalassemia major (TM) [3,4]. Myocardial iron measurement is important for assessing the risk of cardiac complications $[5,6]$, because of the frequency of myocardial siderosis in thalassemia major [2], and the benefit of tailoring appropriate iron-chelating treatment [7-10].

Cardiovascular magnetic resonance (CMR) provides a non-invasive means of measuring the amount of tissue iron. With CMR, the iron deposition results in shortening of proton relaxation times and both $\mathrm{T} 2$ and $\mathrm{T} 2 *$ measurements have been exploited to assess iron overload $[7,11]$. Myocardial T2* is fast and simple to implement and has demonstrated good reproducibility in assessing tissue iron content [12-14]. A similar T2 sequence, however, is technically more difficult, and early attempts at implementation were unsatisfactory for myocardial iron measurements due to problems associated with hardware constraints, flow, cardiac motion, and noise $[15,16]$. However, T2 is known to vary with myocardial iron $[17,18]$, and there may be potential advantages of $\mathrm{T} 2$ over $\mathrm{T} 2 *$ for the avoidance of problems caused by factors such as shimming and local susceptibility. There is also interest in comparing the myocardial $\mathrm{T} 2{ }^{*}$ with $\mathrm{T} 2$ to discover if additional useful clinical information can be gleaned as to the chemical state of the stored iron. For this purpose, a breath-hold T2 technique has been developed and recently reported [19]. This T2 technique has demonstrated good interstudy reproducibility in London. However, in order to be applicable in healthcare on a wider scale, its transferability between scanners of different centers must be established, but no data on this challenging issue is available to date. We now describe the results of the transfer of this technique to different scanners at 4 different centers in different countries.

\section{Methods \\ MR protocols and study population}

The standard center in London used a 1.5T Siemens Sonata scanner. Four other international centers using 1.5T MR scanners were involved in this study. Scanner details were as follows: Center 1, Siemens Sonata (Hong Kong, China); Center 2, Siemens Avanto (Philadelphia, USA); Center 3 Siemens Avanto (Singapore); Center 4, Siemens Symphony Quantum (Izmir, Turkey). The breath-hold black blood T2 sequence developed at London center was installed on each local scanner. The pulse sequence details and methods of 22 calculation have been previously described [19]. In brief, all centers used a fourelement cardiac phased array coil to image a single $10 \mathrm{~mm}$ mid-ventricular short axis slice at 12 echoes times (ranging from $4.8 \mathrm{~ms}$ to $163.2 \mathrm{~ms}$, increment $14.4 \mathrm{~ms}$ ) with ECG gating. Double inversion recovery pulses were applied to suppress the blood signal and data was acquired every other cardiac cycle. For T2 measurement, a region of interest (ROI) was chosen in the left ventricular septum individually. The mean signal intensity of ROI was measured for each of the images, and the data were plotted against the TEs to form a decay curve. The monoexponential decay model and the nonlinear curve fitting algorithm were used to fit the curve to obtain T2 measurement. The sequence parameters were kept identical in all centers although small variations would not be expected to affect the T2 measurement.

A total of 34 (mean age $32 \pm 9$ years) TM patients (10 from Hong Kong, 10 from Singapore, 9 from Philadelphia, 5 from Izmir) were studied. For local interstudy reproducibility, these patients were scanned twice at their local centers within one week. All patients were subsequently rescanned at the standardization center at London (intersite reproducibility) within four weeks of their original scans. These patients had been regularly transfused since early childhood or since the introduction of deferoxamine, and were receiving regular iron chelation. Ethical approval was granted at the standard center and all local centers involved. All patients gave written informed consent.

\section{Statistics}

To quantify both interstudy reproducibility and intersite transferability, the coefficient of variation was calculated $(\mathrm{CoV})$, defined as standard deviation of the differences between the two separate measurements, divided by their mean and expressed as a percentage. Mean differences in $\mathrm{T} 2$ between scans are also quoted as a measure of bias. Summary data were expressed with 95\% confidence intervals and displayed graphically using scatter plots with line of identity and Bland-Altman plots. Group data were compared using Friedman's test. A $p$ value of $<0.05$ was considered statistically significant.

\section{Results}

Myocardial T2 measurements (two at each local site and one in London) were $46.4 \pm 26.3 \mathrm{~ms}, 46.4 \pm 26.1 \mathrm{~ms}$ and $46.3 \pm 26.4 \mathrm{~ms}$ respectively. Friedman's test showed no significant difference $(\mathrm{p}=0.87, \mathrm{n}=34$ ) between these three $\mathrm{T} 2$ measurements.

\section{Local interstudy reproducibility}

The mean difference was $-0.06 \mathrm{~ms}$ and the CoV for local interstudy reproducibility was found to be $4.4 \%$. These values are consistent with those of our previous published data [19]. There was no bias between the two measurements (Figure 1).

\section{Intersite reproducibility}

The mean difference was $-0.07 \mathrm{~ms}$ and the $\mathrm{CoV}$ for intersite reproducibility was found to be $5.2 \%$. These values were similar to those of local interstudy reproducibility mentioned above. This demonstrates good agreement 

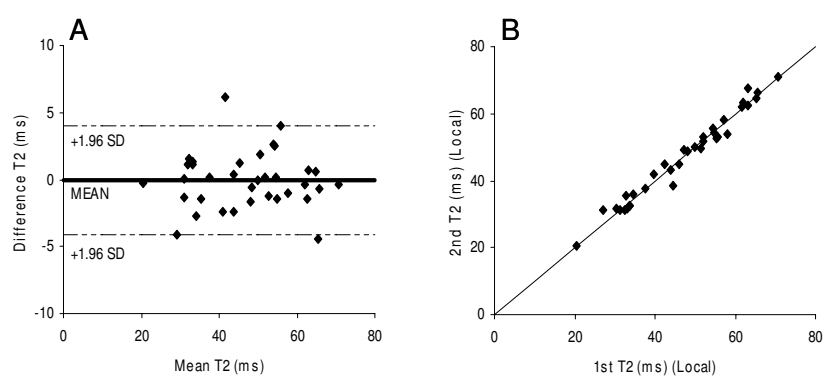

Figure I

Assessment of interstudy reproducibility at the centers $(\mathbf{n}=34)$. A) Bland-Altman plot of the myocardial T2 values obtained locally twice within a week, with the $95 \%$ confidence intervals shown as a dotted line. B) Scatter plot of the myocardial T2 values obtained locally twice within a week. The diagonal line shows the line of identity.

between the standard center scanner and the local scanners at each center and no bias was found (Figure 2).

\section{Discussion}

This study shows that the myocardial $\mathrm{T} 2$ values using the recently developed breath-hold T2 sequence agree very well between 1.5 Tesla scanners in different locations around the world. This demonstration of transferability suggests that this technique could be further disseminated worldwide, should its clinical applicability be demonstrated in iron overload conditions. Although the iron deposition affects both $\mathrm{T} 2$ and $\mathrm{T} 2 *$ relaxation times, $\mathrm{T} 2$ is not affected by extrinsic magnetic field inhomogeneity. Therefore, T2 in principle might provide more accurate measurements. Nevertheless, T2* has substantial clinical validation both in heart and liver suggesting that the potential limitations are more theoretical than real.[19] One potential advantage of $\mathrm{T} 2$ might be to perform robust multi-segmental analysis to explore the regional iron distribution, because $\mathrm{T} 2 *$ is currently limited to the septum to avoid susceptibility effects from the anterior and posterior cardiac veins and lungs. This may in due course improve our understanding of how other factors affect T2* across the myocardium. It is possible that different chemical forms of iron in the tissue could have differential effects between $\mathrm{T} 2$ and $\mathrm{T} 2 *$, and measurement of both parameters might be useful if chelators access different forms of iron at different rates. From our studies of both $\mathrm{T} 2 *$ and $\mathrm{T} 2$, it is likely that both parameters can assess the tissue iron accurately in the heart using state-of-the-art sequences, and combined analysis may provide more information for patient management. Further research is needed to determine this. One limitation of this study was that only Siemens scanners were involved, and results from other scanners would be useful. There is no substan-
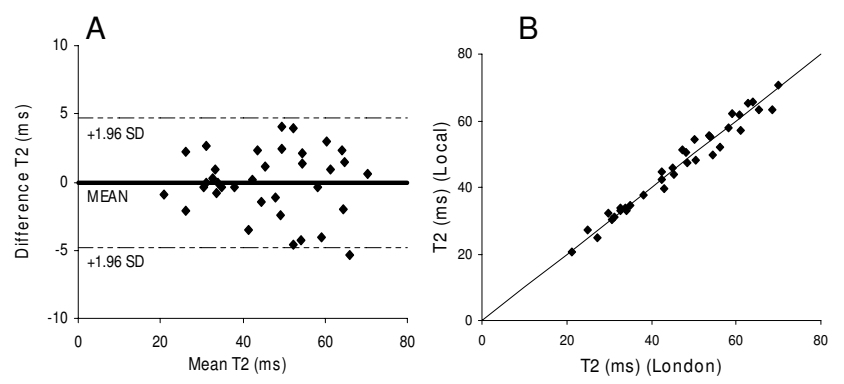

Figure 2

Assessment of intersite reproducibility between local centers and the standard center in London $(n=34)$. A) Bland-Altman plot of the myocardial T2 values obtained locally and at London within a month, with the $95 \%$ confidence intervals shown as a dotted line. B) Scatter plot of the myocardial T2 values obtained locally and at London within a month. The diagonal line shows the line of identity.

tial barrier to this once the sequence has been adapted by other manufacturers.

To conclude, this study has demonstrated the good intersite reproducibility of the breath-hold $\mathrm{T} 2$ technique between 1.5T Siemens MR scanners at different centers across different countries. With widespread application, this T2 technique might yield new insights into the assessment of myocardial iron and may have clinical application possibly in conjunction with $\mathrm{T} 2 *$.

\section{Competing interests}

The author(s) declare that they have no competing interests.

\section{Acknowledgements}

This work was supported by NIH Grant (ROI DK66084-0I) and Novartis Oncology at Basel.

\section{References}

I. Tanner MA, Galanello R, Dessi C, Westwood MA, Smith GC, Nair SV, Anderson LJ, Walker JM, Pennell DJ: Myocardial iron loading in patients with thalassemia major on deferoxamine chelation. J Cardiovasc Magn Reson 2006, 8:543-547.

2. Maceira AM, Prasad SK, Khan M, Pennell DJ: Normalized left ventricular systolic and diastolic function by steady state free precession cardiovascular magnetic resonance. J Cardiovasc Magn Reson 2006, 8:417-526.

3. Olivieri NF, Nathan DG, MacMillan JH, Wayne AS, Liu PP, McGee A, Martin M, Koren G, Cohen AR: Survival in medically treated patients with homozygous beta-thalassemia. N Engl J Med 1994, 33 1:574-578.

4. Borgna-Pignatti C, Rugolotto S, De Stefano P, Zhao H, Cappellini MD, Del Vecchio GC, Romeo MA, Forni GL, Gamberini MR, Ghilardi R, Piga A, Cnaan A: Survival and complications in patients with thalassemia major treated with transfusion and deferoxamine. Haematologica 2004, 89: I I87-II 93.

5. Tanner MA, Porter JB, Westwood MA, Nair SV, Anderson LJ, Walker JM, Pennell DJ: Myocardial T2* in patients with cardiac failure secondary to iron overload. Blood 2005, 106(Suppl):40B. (Abstract 3838a) 
6. Wood JC, Tyszka JM, Carson S, Nelson MD, Coates TD: Myocardial iron loading in transfusion- dependent thalassemia and sickle cell disease. Blood 2004, 103:1934-1936.

7. Anderson LJ, Wonke B, Prescott E, Holden S, Walker JM, Pennell DJ: Comparison of effects of oral deferiprone and subcutaneous desferrioxamine on myocardial iron levels and ventricular function in beta thalassemia. Lancet 2002, 360:516-520.

8. Anderson LJ, Westwood MA, Holden S, Davis B, Prescott E, Wonke B, Porter JB, Walker JM, Pennell DJ: Myocardial iron clearance during reversal of siderotic cardiomyopathy with intravenous desferrioxamine: A prospective study using T2* cardiovascular magnetic resonance. $\mathrm{Br} J$ Haematol 2004, I 27:348-355.

9. Pennell DJ, Berdoukas V, Karagiorga M, Ladis V, Piga A, Aessopos A, Gotsis ED, Tanner MA, Smith GC, Westwood MA, Wonke B, Galanello R: Randomized controlled trial of deferiprone or deferoxamine in beta-thalassemia major patients with asymptomatic myocardial siderosis. Blood 2006, 107:3738-3744.

10. Tanner MA, Galanello R, Dessi C, Smith GC, Westwood MA, Agus A, Roughton M, Assomull R, Nair SV, Walker JM, Pennell DJ: A randomized, placebo controlled, double blind trial of the effect of combined therapy with deferoxamine and deferiprone on myocardial iron in thalassemia major using cardiovascular magnetic resonance. Circulation 2007, I I5: 1876-1884.

1I. Wood JC: Magnetic resonance imaging measurement of iron overload. Curr Opin Hematol 2007, I 4: 183-190.

12. Westwood MA, Anderson LJ, Firmin DN, Gatehouse PD, Lorenz CH, Wonke B, Pennell DJ: Interscanner reproducibility of cardiovascular magnetic resonance T2* measurements of tissue iron in thalassemia. J Magn Reson Imaging 2003, 18:616-620.

13. Westwood MA, Firmin DN, Gildo M, Renzo G, Stathis G, Markissia $K$, Vasili B, Pennell DJ: Intercenter reproducibility of magnetic resonance T2* measurements of myocardial iron in thalassaemia. Int I Cardiovasc Imaging 2005, 2 1:53 I-538.

14. Tanner MA, He T, Westwood MA, Firmin DN, Pennell DJ, Thalassemia International Federation Heart T2* Investigators: Multicenter validation of the transferability of the magnetic resonance T2* technique for the quantification of tissue iron. Haematologica 2006, 91 : 1388-1391.

15. Mavrogeni SI, Gotsis ED, Markussis V, Tsekos N, Politis C, Vretou E, Kermastinos $D$ : T2 relaxation time study of iron overload in bthalassemia. MAGMA 1998, 6:7-12.

16. Papanikolaou N, Ghiatas A, Kattamis A, Ladis C, Kritikos N, Kattamis $C$ : Non-invasive myocardial iron assessment in thalassaemic patients. T2 relaxometry and magnetization transfer ratio measurements. Acta Radiol 2000, 41:348-35I.

17. Ghugre NR, Enriquez CM, Gonzalez I, Nelson MD Jr, Coates TD, Wood JC: MRI detects myocardial iron in the human heart. Magn Reson Med 2006, 56:68I-686.

18. Wood JC, Otto-Duessel M, Aguilar M, Nick H, Nelson MD, Coates TD, Pollack H, Moats R: Cardiac iron determines cardiac T2*, T2, and TI in the gerbil model of iron cardiomyopathy. Circulation 2005, I I 2:535-543.

19. He T, Gatehouse PD, Anderson LJ, Tanner M, Keegan J, Pennell DJ, Firmin DN: Development of a novel optimized breathhold technique for myocardial T2 measurement in thalassemia. J Magn Reson Imaging 2006, 24:580-585.

Publish with Biomed Central and every scientist can read your work free of charge

"BioMed Central will be the most significant development for disseminating the results of biomedical research in our lifetime. "

Sir Paul Nurse, Cancer Research UK

Your research papers will be:

- available free of charge to the entire biomedical community

- peer reviewed and published immediately upon acceptance

- cited in PubMed and archived on PubMed Central

- yours - you keep the copyright

Submit your manuscript here:

http://www.biomedcentral.com/info/publishing_adv.asp
BioMedcentral 